\title{
Assessment of Hearing Impairment Using Brainstem Evoked Response Audiometry (BERA) In Neonates with Various Otonoxious Risk Factors
}

\author{
*Dr.Jose.O**Dr.Sreelatha. P. R *** Dr Rani R Nath \\ * Assistant Professor Dept of Pediatrics Govt. T.D Medical college Alappuzha, \\ ** Assistant Professor Dept of PediatricsGovt. T.D Medical college Alappuzha \\ *** Junior Resident Dept. of Pediatrics govt. T.D.Medical College, Alappuzha
}

\begin{abstract}
Objectives: The aim of this study was to assess hearing impairment in newborn having otonoxious risk factors. Methods: 270 newborns with risk factors for hearing impairment were subjected to BERA initially with90 dB and subsequently stimuli at decreasing frequencies i.e. 75, 60, $45 \mathrm{~dB}$ will be presented to each ear at an intensity of $90 \mathrm{~dB}$ hearing level. An infant will be considered as passed the test if wave $V$ was present at $30 \mathrm{~dB}$ in both ears or in one ear at $30 \mathrm{~dB}$ and in the other at $45 \mathrm{~dB}$.

Results: Out of the 270 newborns, BERA was found to be impaired in 48 cases with increased hearing threshold, remaining 222 neonates had normal hearing threshold of $30 \mathrm{~dB}$ bilaterally and $45 \mathrm{~dB}$ in one ear and $30 \mathrm{~dB}$ in the other ear.Very low birth weight babies with impaired hearing was $25 \%$, hyperbilirubinaemia in exchange range having hearing impairment were 45\%, newborns with sepsis and hearing impairment were $32.5 \%$, however after multiple logistic regression analysis sepsis was found to have strong relationship with hearing impairment p value $<0.001$ and OR 10.991. Elevated auditory threshold was found more frequently in neonates with multiple clinical adverse factors than in those having single risk factor (36/133 Vs 12/137, p $<0.001$, OR 3.87).

Conclusion: Proportion of newborn with impaired BERA was high in high risk newborn when compaired to general population. Sepsis, very low birth weight and hyperbilirubinaemia in exchange range were found to have significant hearing impairment.
\end{abstract}

Keywords: BERA, risk factors, auditory threshold

\section{Introduction}

As per WHO report, there are about 250 million deaf people in the world and is the second most common cause of disability. According to Centre for Disease Control (CDC), Hearing screening and follow- up survey 2009, 1.4 per 1000 babies screened (Range 0 - 4.6 per 1000 babies screened) have hearing impairment. Prevalence and incidence rate of hearing loss in India is quiet alarming. Studies show varying prevalence rates from $1 \%$ to as high as $40 \%{ }^{[2]}$.

One in 1000 children is born with a hearing impairment significant enough to impede the learning of speech \& language ${ }^{[3]}$. Joint Committee on Infant Hearing $(\mathrm{JCIH})^{[4]}$ promulgated a list of specific risk factors to identify infants at risk for hearing impairment for careful follow - up and assessment. Several studies have shown that when children are identified with hearing loss at birth and received intervention before the age of 6 months, they catch up with their normal peers and demonstrate essentially normal language development. Conversely, children who are identified with hearing loss later in life and receive intervention after age of 6 months, especially those with severe to profound hearing loss and with multiple handicaps, struggle to catch up with their normal peers Moreover, children identified later than 6 months of age may lag in their speech ,language, and auditory development well into early and later elementary years.

Brainstem Evoked Response Audiometry (BERA) has expanded the objective testing of hearing functions. This is an effective and simple method that requires less co-operation of the patient and measures the specific part of auditory pathway.

Review Of Literature - Retrospective studies of large universal newborn hearing screening programs have shown that permanent hearing loss is one of the most common abnormalities present at birth. In 1999, the American Academy of Pediatrics Task Force on Newborn and Infant Hearing stated, "significant bilateral hearing loss has been shown to be present in approximately 1 to 3 per 1000 newborns in the well-baby nursery population, and in approximately 2 to 4 per 1000 infants in the intensive care unit population" ${ }^{[6]}$. In the at-risk population, which includes neonates who spend time in the newborn intensive care unit (NICU), the occurrence of hearing loss is even higher. Risk factors for hearing loss specifically found in this population include, LBW babies ,PT babies ,babies on ventilation, hyperbilirubinemia, and exposure to ototoxic medications. 
Since hearing loss is not a visible disability, it will go unnoticed upto 18 months, especially in children who have no medical conditions and/ or other disabilities. Professional leadership in the subspecialty of infant hearing and early detection has been largely provided by the Joint Committee of Infant Hearing(JCIH). Initially, the JCIH did not recommend universal hearing screening for all newborn (JCIH .1972), instead the endorsed High Risk Register(HRR) for screening newborn who should receive hearing evaluation. They revised and expanded the high risk criteria for hearing screening in 1982, 1990 and 1994. Unfortunately only about 50\% of infant with sensorineural hearing losses were identified by using the HRR. Since the goal should be $100 \%$, consensus has been reached that the universal detection of newborn hearing loss requires screening of all newborns.In 1994, the JCIH issued their statement that endorsed that "the goal of universal detection of infants with hearing loss as early as possible. All infants with hearing loss should be identified by three months of age and receive intervention by six months of age".

The American Academy of Pediatrics (AAP) released a statement in 1999 that recommended newborn hearing screening and intervention. Next year 2000, citing advances in screening technology, the JCIH endorsed the universal screening of all infant through an integrated, inter disciplinary system of Early Hearing Detection and Intervention(EHDI). Identification and intervention before age 6 months can have a significant impact on the development of expressive and receptive language. The finding that language scores were not significantly different between the children identified later truly establishes the critical period of early identification and intervention to be within the first 6 months of life.

A large NIH-sponsored multi-centre study conducted between 1994 and 1996 evaluated the performance of newborns on OAE and BERA hearing screening and also reported the incidence of risk factors for neonatal hearing loss ${ }^{[21]}$. A total of 4478 graduates from NICUs, 353 well babies with one or more of the risk factors for hearing loss established by the Joint Committee on Infant Hearing in 1994 (which included VLBW), and 2348 well babies with no risk factors were assessed ${ }^{[22]}$. One risk factor was found in $33.2 \%$ of NICU infants, and two or more in $26.2 \%$. Within the NICU population, the most common risk factors were aminoglycoside use (44.4\%), VLBW (17.8\%), mechanical ventilation for more than 5 days (16.4\%), and low Apgar scores (13.9\%).

Bera - BERA is not a direct test of hearing sensitivity, but it has earned a strong clinical reputation as a tool to evaluate the integrity of the auditory pathway from external ear to the lower brainstem. BERA is an objective way of eliciting brain stem potentials in response to audiological click stimuli. These waves are recorded by electrodes placed over the scalp BERA are potentials recorded from the ear and vertex in response to a brief audiometry stimulation to assess the conduction through the auditory pathway up to midbrain.

It consists of 5-7 vertex positive peaks that normally occur within 10 milliseconds after the presentation of a stimuli. Responses are usually displayed with positive peaks, reflecting activity toward vertex positive and these peaks are labeled with Roman Numerals I through VII.

Wave I: It is the representation of the compound auditory nerve action potential in the distal portion of cranial nerve VIII. The response is believed to originate from afferent activity of the CN VIII fibers (first-order neurons) as they leave the cochlea and enter the internal auditory canal.

Wave II: It is generated by the proximal VIII nerve as it enters the brain stem.

Wave III: It arises from second-order neuron activity (beyond CN VIII) in or near the cochlear nucleus.

Wave IV: Arise from pontine third-order neurons. mostly located in the superior olivary complex, but additional contributions may come from the cochlear nucleus and nucleus of lateral lemniscus, often shares the same peak with wave V.

Wave V: Generation of wave V likely reflects activity of multiple anatomic auditory structures. It believed to originate from the vicinity of the inferior colliculus. Sharp positive peak of wave V arises mainly from the lateral lemniscus following slow negative wave represents dendritic potential in the inferior colliculus.

\section{Pathophysiology of hearing impairment in High risk infants:}

Although much has been written about the epidemiology of childhood hearing impairment, the relative incidence of different causes of hearing impairment in children still remains confusing. Many epidemiologic studies in the United States and Europe suggest that at least all cases of hearing impairment are due to genetic factors $^{[29]}$. Of the remainder, about $20-25 \%$ are typically assigned to prenatal, perinatal or postnatal environmental causes and $25 \%-30 \%$ comprises sporadic cases of unknown cause.

\section{Ototoxic Drugs}

The two preferentially vestibulotoxic agents are gentamicin (the most widely used) and tobramycin. Aminoglycosides that are more selective to the cochlea are neomycin, kanamycin and amikacin. These agents produce irreversible hearing loss by causing hair cell death. They block ionic currents through the mechanoelectrical transduction channels in the stereocilia ${ }^{[37]}$ and are taken up into the hair cells through apical endocytosis. 
It is estimated that $6 \%-16 \%$ of patients who receive aminoglycosides suffer sensorineural hearing $\operatorname{loss}^{[27]}$. In the cochlea, polyphosphoinositides in hair cell membranes are affected by aminoglycosides (toxic metabolites) resulting in altered permeability and magnesium ion loss, leading to cell death.

\section{Prematurity}

Less than 37 completed weeks (259 days). Several studies have looked at BERA specifically in the preterm infant. These studies have reported the behavior of wave $\mathrm{V}$ as a function of age and signal intensity with reliability and confidence. Estimates of hearing loss in the full-term child ranges from $0.26 \%$ to $0.5 \%$. in the preterm infant, hearing loss occurs more frequently with estimates ranging from 0 to $15 \%$

Low Birth Weight Babies- an association between birth weight $<1500 \mathrm{~g}$ (very low birth weight (VLBW)) and hearing loss has been long recognised. The prevalence of failed hearing screening in neonates with VLBW is significantly higher than in neonates with normal birth weight because they experience higher rates of transient middle ear fluid accumulation and conductive hearing loss. However, these patients are commonly exposed to other risk factors for hearing loss such as ototoxic drugs, hypoxia and hyperbilirubinaemia, which may lead to early or delayed-onset sensorineural hearing loss as well as progression of a mild pre-existing sensorineural hearing loss years after hospital discharge. One study compared results of newborn hearing screening tests of 1714 infants 36 weeks or older in an NICU and 25288 infants from the wellbaby nursery. Patients were considered to have failed their OAE screening test when either one or both ears had hearing loss. Seven percent of infants from the NICU failed the test, whereas only $1.9 \%$ of the infants from the well-baby nursery failed. Among the infants from the NICU, those with VLBW had a failure rate of $31.6 \%$.

\section{Hyperbilirubinemia}

Hyperbilirubinemia during the neonatal period with associated kernicterus or bilirubin encephalopathy has been etiologically tied to SNHL. Kernicterus is a neurological syndrome resulting from the deposition unconjugated bilirubin in the basal ganglia and brainstem nuclei . Factors that influence bilirubin toxicity to the brain cells of newborn are complex and incompletely understood Bilirubin levels that are toxic to one infant may not be toxic to another, or even to the same infant in different clinical circumstances.

It is estimated that $8.5 \mathrm{mg}$ of bilirubin will bind tightly to $1 \mathrm{~g}$ of albumin, although this binding capacity is less in small and sick prematures. FFAs and certain drugs interfere with bilirubin binding to albumin, although acidosis affects bilirubin solubility and its deposition into brain tissue. Anoxia, hypercarbia and hyperosmolarity increase the permeability of BBB and increase deposition of bilirubin in the brain. Respiratory acidosis also increase bilirubin brain deposition

\section{Bilirubin toxicity and the low-birth-weight infant.}

Initial early studies of babies of 1,250 to $2,500 \mathrm{~g}$ and 28 to 36 weeks' gestational age showed no relation between neurologic damage and bilirubin levels $>18$ to $20 \mathrm{mg} / \mathrm{dL}$. Later studies, however, began to report "kernicterus" at autopsy or neurodevelopmental abnormalities at follow-up in premature infants $<1,250 \mathrm{~g}$ who had bilirubin levels previously thought to be safe (e.g., $<10$ to $20 \mathrm{mg} / \mathrm{dL}$ ). Because kernicterus in preterm infants is now considered uncommon, hindsight suggests that this so-called "low bilirubin kernicterus" was largely due to factors other than bilirubin alone.

Despite the progress made in clinical management, there is no agreement as to what constitutes a "safe" level of bilirubin. Early detection of bilirubin neurotoxicity may be possible by use of BERA. BERA can be also useful for screening hyperbilirubinemic full-term and premature infants for SNHL and incorporated into the assessment of need for exchange transfusions.

\section{Hypoxic Ischemic Encephalopathy}

Increased risk for SNHL has been described among infants who experienced hypoxia or anoxia during prenatal period, resulting from factors such as placental insufficiency, mechanical compression of the umbilical cord, or neonatal seizures ${ }^{[29]}$. When an infant has low APGAR scores (0-3) that permit longer than 5 minutes, severe acidosis $\left(\mathrm{P}^{\mathrm{H}} \leq 7.0\right)$, neonatal encephalopathy and some degree of systemic organ injury, the infant can be diagnosed as having had perinatal asphyxia significant enough possibly to cause neurologic sequelae. The brainstem is affected frequently in newborns both in term and in preterm infant. Hearing loss is secondary to hypoxic injury to brain stem dorsal cochlear nuclei

\section{Aim}

1. To estimate the proportion of neonates having hearing impairment among those with otonoxious risk factors, using Brainstem Evoked Response Audiometry.

2. To find out factors associated with hearing impairment. 
Materials And Methods- Study Design : Descriptive study.

Study Population- High risk newborns admitted in N ICU ,department of pediatrics, T.D.Govt.Medical college, Alappuzha.

Study Setting: Babies admitted in In Born Nursery or Out Born Nursery of the Department of the department of pediatrics, T.D. Medical College, Alappuzha

Period of study : January 2014-December 2014

Sample size: According to a study done by A.K. Gupta, N.K. Anand and Hans Raj prevalence of hearing impairment among neonates with otonoxious risk factors was $27 \%$.Using this information sample size has been estimated to be 270 using the formula $\mathrm{Z} \alpha^{2} \mathrm{PQ} / \mathrm{d}^{2}$

$\mathrm{Z} \alpha=1.96 ; \mathrm{P}=27 ; \mathrm{Q}=100-27=73 ; \mathrm{d}$ the precision is $20 \%$ of $\mathrm{P}$.

Study subjects- Inclusion criteria 1.Prematurity ( $<36$ weeks),2.Very Low birth weight $(<1.5 \mathrm{~kg}), 3 . \mathrm{HIE}$ 4.Hyperbilirubinaemia in exchange range,5. ototoxic drugs use,6.sepsis 7.mechanical ventilation intra-uterine infection, 8.meningitis

Exclusion criteria- 1.Craniofacial malformation 2.Middle ear infections. 3.Family history of deafness

\section{Study Procedure}

After obtained ethical committee clearances from Govt T D Medical College Alappuzha ,the study was conducted in the department of pediatrics Govt T D Medical College Alappuzha . In this study Newborn \&infants fulfilling the inclusion criteria will be enrolled and studied during discharge. A written informed consent will be obtained from one of the parents before enrolment. Those with impaired BERA will be sent to the audiologist for purpose of further evaluation and management.

\section{Procedure of Brain Stem Evoked Response Audiometry}

Newborns were sedated with syrup Trichlofos (pedichoryl) $.5-1 \mathrm{mg} / \mathrm{kg}$ body weight. The skin at the point of placement of electrodes were cleaned. Recording of BERA was carried out in a quiet room. Surface electrodes were placed at the vertex $\left(\mathrm{C}_{\mathrm{Z}}\right)$, both mastoids (Ai and $\mathrm{Ac}$ ) and forehead . The resistance was kept below $5 \mathrm{~K}$. Sweep velocity of $10 \mathrm{~mm} / \mathrm{sec}$. and click acoustic stimuli at a rate of $10 / \mathrm{sec}$ will be presented to each ear at an intensity of $90 \mathrm{~dB}$ hearing level. Subsequently stimuli at decreasing frequencies i.e. 75, 60, $45 \mathrm{~dB}$ will be presented to each ear and recordings taken. Masking sound of $40 \mathrm{~dB}$ will be used for the non-stimulated ear. Electrical activity being filtered and averaged to 2000 responses. 2000 responses will be averaged and minimum of two tests performed for reproducibility. $30 \mathrm{~dB}$ taken as the normal threshold of wave V. An infant will be considered as passed the test if wave $\mathrm{V}$ was present at $30 \mathrm{~dB}$ in both ears or in one ear at $30 \mathrm{~dB}$ and in the other at $45 \mathrm{~dB}$.

\section{Statistical Analysis}

Data were analyzed using computer software, Statistical Package for Social Sciences (SPSS) version 16. Data are expressed in its frequency and percentage. To elucidate the associations and comparisons between different parameters, Chi square $\left(\chi^{2}\right)$ test was used as nonparametric test. Multivariate logistic regression analysis was performed to assess the risk factors (Odds ratio) of different factors in the study. For all statistical evaluations, a two-tailed probability of value, $<0.05$ was considered significant.

\section{Observations And Results}

The present study was conducted in Department of Pediatrics, T.D.Medical College, Alappuzha. 270 high risk newborn were analysed for the study. Among the 270 children $61.5 \%$ were males and $38.5 \%$ were females. The male to female ratio was 1.6:1. Out of 270 high risk infants ,preterms constituted 52.6\%; very low birth weight $53.7 \%$, hyperbilirubinaemia in exchange $12.2 \%$,ototoxic drug usage $28.9 \%$, birth asphyxia $10.3 \%$, intrauterine infection $1.5 \%$, sepsis $46.7 \%$, mechanical ventilation $20 \%$, meningitis $27 \%$. Of total 142 preterms 28 i.e. $19.7 \%$ had hearing impairment and in term babies out of total 128,20 babies i.e. $15.6 \%$.p value 0.380 which is not statistically significant. 


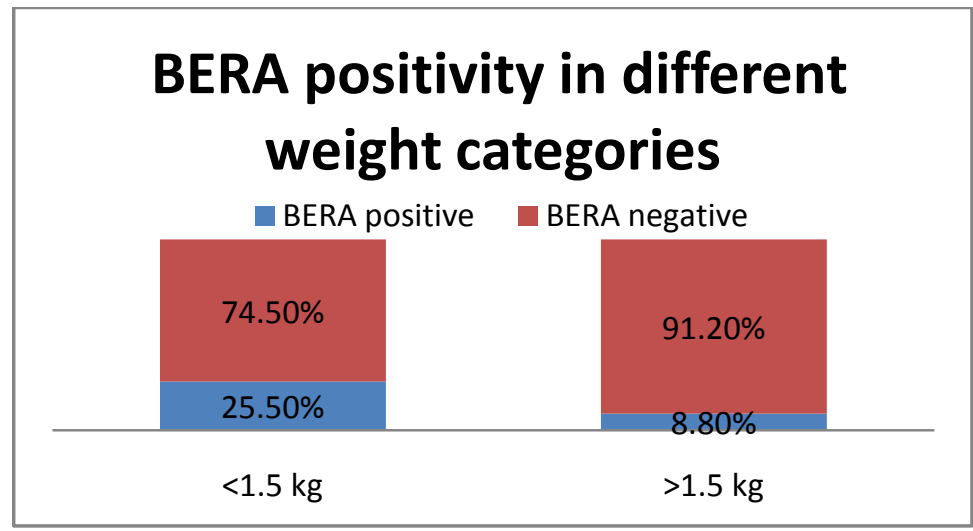

Very low birth weight neonates had more BERA positivity than with weight $>1.5 \mathrm{~kg}$, and the difference is statistically significant. $\mathrm{p}<0.001$

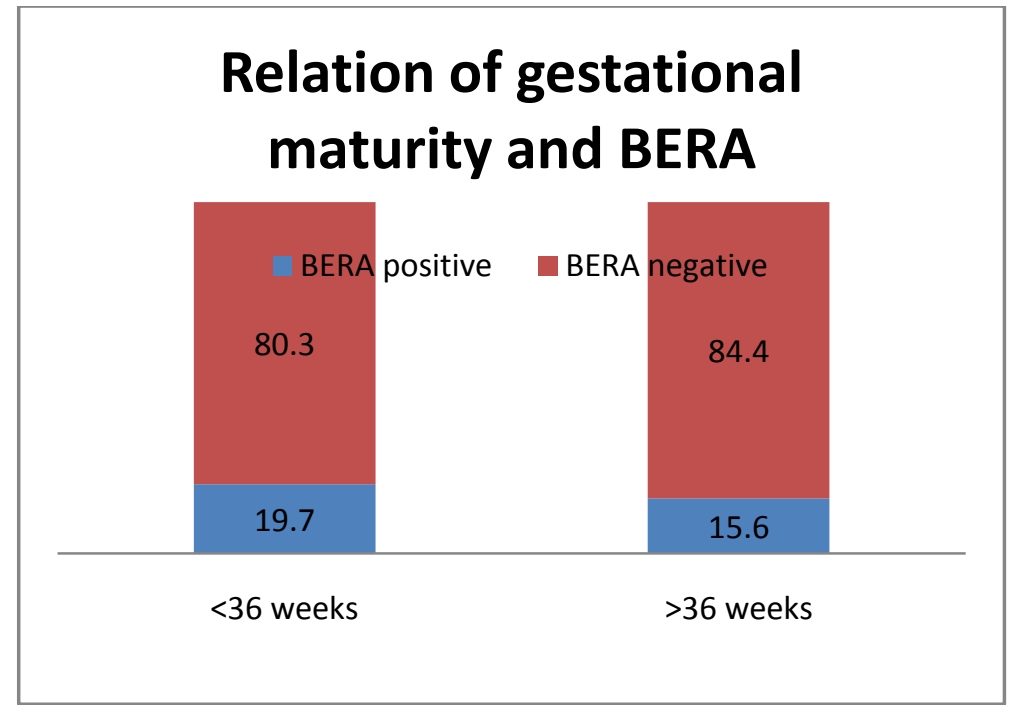

Neonates with ototoxic drug usage with BERA positivity was $21.8 \%$ and negativity $78.2 \%$, but the difference was not statistically significant. $\mathrm{p}=0.271$

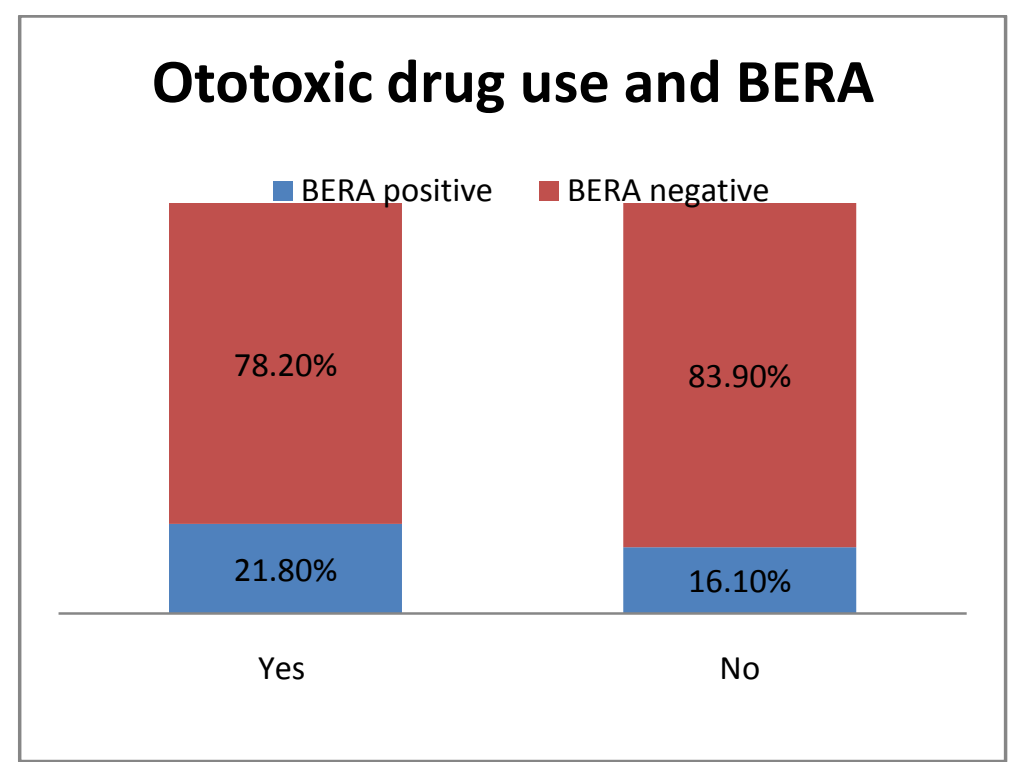

$25 \%$ of neonates with intra-uterine infection had impaired BERA, but it was not statistically significant$\mathrm{p}=0.703$ 


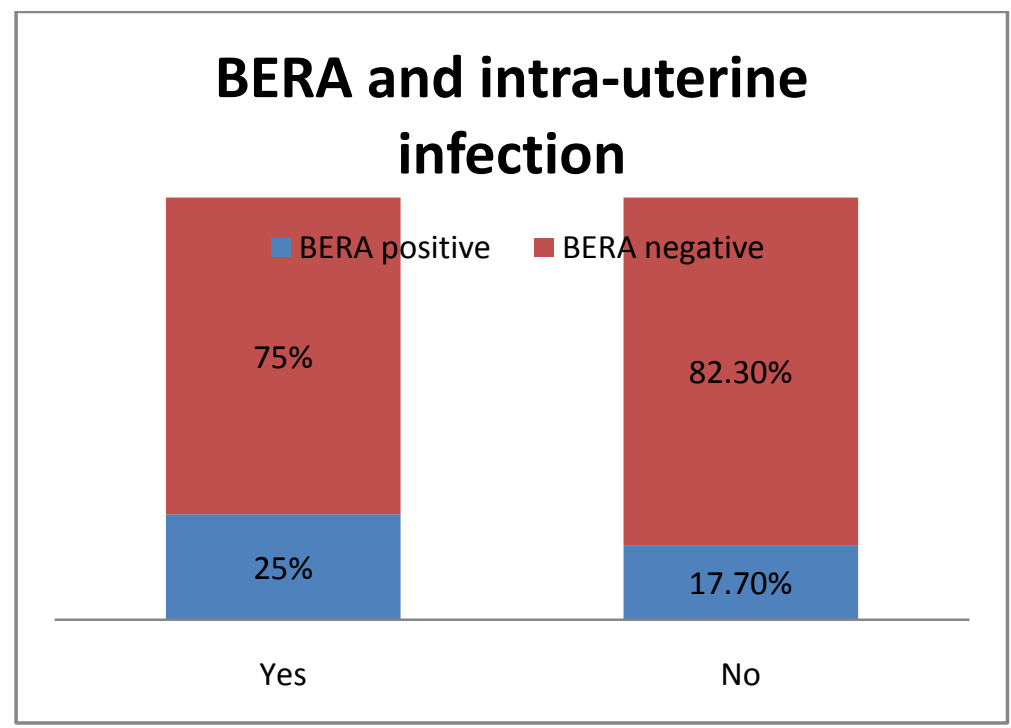

Table 1: proportion of neonates having mechanical ventilation and BERA

\begin{tabular}{|l|l|l|l|}
\hline \multirow{2}{*}{$\begin{array}{l}\text { Mechanical } \\
\text { ventilation }\end{array}$} & \multicolumn{2}{|l|}{ BERA } & \multirow{2}{*}{ Total } \\
\cline { 2 - 3 } & Positive & Negative & \\
\cline { 2 - 4 } & $\mathrm{N}(\%)$ & $\mathrm{N}(\%)$ & $\mathrm{N}(\%)$ \\
\hline Yes & $12(22.2)$ & $42(77.8)$ & $54(100)$ \\
\hline No & $36(16.7)$ & $180(83.3)$ & $216(100)$ \\
\hline
\end{tabular}

Among 54 neonates who underwent mechanical ventilation 22.2\% had impaired BERA, and it was not statistically significant.

Table 2: proportion of neonates with meningitis and BERA

\begin{tabular}{|l|l|l|l|}
\hline \multirow{2}{*}{ Meningitis } & \multicolumn{2}{|l|}{ BERA } & \multirow{2}{*}{ Total } \\
\cline { 2 - 3 } & Positive & Negative & \\
\cline { 2 - 4 } & $\mathrm{N}(\%)$ & $\mathrm{N}(\%)$ & $\mathrm{N}(\%)$ \\
\hline Yes & $16(21.9)$ & $57(78.1)$ & $73(100)$ \\
\hline No & $32(16.2)$ & $165(83.8)$ & $197(100)$ \\
\hline
\end{tabular}

$\mathrm{p}=0.279$. Among 73 cases of meningitis $21.9 \%$ cases had impaired BERA and it was not statistically significant.

Table 3 : proportion of newborn with hyperbilirubinaemia in exchange range

\begin{tabular}{|l|l|l|l|}
\hline \multirow{2}{*}{$\begin{array}{l}\text { Hyperbilirubinemia in } \\
\text { exchange range }\end{array}$} & BERA & Tegative \\
\cline { 2 - 4 } & Positive & $\mathrm{N}(\%)$ & $\mathrm{N}(\%)$ \\
\cline { 2 - 4 } & $\mathrm{N}(\%)$ & $18(54.5)$ & $33(100)$ \\
\hline Yes & $15(45.5)$ & $204(86.1)$ & $237(100)$ \\
\hline No & \multicolumn{2}{|c|}{$33(13.9)$} & \\
\hline
\end{tabular}

$\mathrm{p}<0.001 \quad \mathrm{OR}=5.152 \quad 95 \% \mathrm{CI}=2.367-11.212$

33 neonates had hyperbilirubinaemia in the exchange range of which $45.5 \%$ had hearing impairment according to BERA, was statistically significant.

Table 5 : independent risk factors after multiple logistic regression analysis

\begin{tabular}{|c|c|c|c|c|}
\hline \multirow[t]{2}{*}{ Variables } & \multirow[b]{2}{*}{$\mathrm{p}$} & \multirow[b]{2}{*}{ OR } & \multicolumn{2}{|c|}{$95 \%$ C.I.for OR } \\
\hline & & & Lower & Upper \\
\hline Sepsis & $<0.001$ & 10.991 & 4.502 & 26.830 \\
\hline Very low birth weight & $<0.001$ & 4.986 & 2.241 & 11.093 \\
\hline $\begin{array}{l}\text { Hyperbilirubinaemia } \\
\text { exchange range }\end{array}$ & 0.006 & 3.547 & 1.436 & 8.758 \\
\hline
\end{tabular}

While checking individual risk factors using multiple logistic regression analysis-sepsis, very low birth weight and bilirubin in the exchange range were found to have significant relation with impaired BERA.Single Vs Multiple risk factors associated with Abnormal BERA 
Table 6 : showing frequency in the group with multiple risk factors and single risk factor

\begin{tabular}{|l|l|l|l|l|l|l|}
\hline \multirow{2}{*}{ Risk factors } & \multicolumn{3}{|l|}{ BERA } & Negative & \multicolumn{2}{|l|}{ Total } \\
\cline { 2 - 7 } & Positive & $\%$ & N & $\%$ & N & \\
\hline Single & 12 & 8.8 & 125 & 91.2 & 137 & \\
\hline Multiple & 36 & 27.1 & 97 & 72.9 & 133 & \\
\hline Total & 48 & & 222 & & 270 & 100 \\
\hline
\end{tabular}

$. P<0.001$ OR $=3.87$

\section{Discussion}

During study period of 1 year 460 NICU admissions were there. 300 neonates with risk fac40 newborns were extremely sick hence were excluded from the study. 300 newborns had risk factors mentioned in my study. We excluded 26 neonates who died before conducting BERA. 1 had family history of hearing loss ,2 had craniofacial malformations and 1 had evidence of middle ear infection. Remaining 270 newborn were included in the study.

The incidence of hearing impairment in high risk infants according to different statistics ${ }^{[2,]}$ varies from $1 \%$ to $40 \%$. There are several risk factors which are important as precipitatory events, causing hearing impairment in newborn and young infants. The following are among these risk factors- prematurity, low birth weight, asphyxia, use of aminoglycosides, hyperbilirubinemia, prolonged mechanical ventilation, bacterial meningitis, intrauterine infection and craniofacial anomalies ${ }^{[4]}$.

Most of the 9 clinical adverse factors examined in the present study (viz., prematurity <36 wks, LBW $<1500 \mathrm{gm}$, hyperbilirubinaemia in exchange range, ototoxic drugs, HIE, intra-uterine infection, sepsis, mechanical ventilation and meningitis ) have already been recognized to be important for producing hearing impairment in the affected neonates. Certain other well known risk factors such as family history of deafness and babies with congenital intrauterine infections, however, do not appear in our list. Thus our list is not exhaustive with respect to factors that place an infant at risk for hearing loss.

In the present study, abnormal BERA threshold was observed in 48 out of 270 neonates i.e. 17.8\%. Similar high percentage (5-25\%) of abnormal BERA results have been observed in neonates graduating from NICU of other places. Very low birth weight babies had a significant hearing impairment $25.5 \%$ which was similar to the study done by Ira Bergman et al. In Gupta et al.'s study; birth weight $<1500 \mathrm{~g}$ was significantly correlated with the hearing impairment Incidence of hearing impairment in hyperbilirubinaemia in exchange transfusion range cases was $45.5 \%$ most common being mild hearing loss which is comparable to Agarwaland Hans Raj but higher than others. Proportion of newborn with sepsis had hearing impairment $32.5 \%$ was found to be statistically significant, after multiple logistic regression. Sepsis is a known risk factor for hearing loss as described by Jacobson 1985 Detailed analysis of the case records, suggested that abnormalities, however, were found with greater frequency in the group with multiple risk factors than in those with single clinical factor (36/133 vs 12/137), p value <0.001 (table 16). This has been substantiated by other studies also Role of multiple risk factors in producing hearing impairment,however, is not higlighted in the high risk register provided by Joint Committee on infant hearing.On multiple logistic regression analysis, however, only 3 factors have been found to be significantly correlated to hearing impairment in the affected neonates (viz; hyperbilirubinaemia at level exceeding indication for exchange transfusion , birth wcight $(<1500 \mathrm{gm})$ and sepsis. In order of importance, however, sepsis is the single most important adverse factor followed by VLBW and hyperbilirubinaemia in exchange range. Rest of all other factors have been observed to have no significant bearing on the production of hearing impairment.

Rejection of preterm as a risk factor which varied from study done by Samani, Peschiulli and Fior (1990) which requires an explanation, this might be due to inclusion of neonates with advanced gestational age.

\section{Conclusion}

Proportion of hearing impairment among high risk newborn was found to be $17.7 \%$ i.e. 177 in 1000 when compaired to a prevalence of 1-4 in 1000 newborn in the general population. Out of the nine risk factors studied three risk factors viz. sepsis, very low birth weight and hyperbilirubinaemia in exchange range were found to have strong association with hearing impairment.Newborns with multiple risk factors had more chance of hearing impairment when compaired to those with single risk factor. Further studies with larger sample size and controls need to be done to confirm the findings of this study.

Limitations Of The Study-Larger sample size and controls from normal population need to be studied for more significant conclusions.

- Compliance with Ethical committee recommendation from Govt T D Medical college and college committee on research

- Conflict of interest -None

- Source of funding -None

DOI: $10.9790 / 0853-1603022533$

wWw.iosrjournals.org

31 | Page 
- Acknowledgements -the author thanks to Dr.Girija Mohan ,Former HOD Department Of Pediatrics Govt T D Medical College, Dr.Laila Chacko, Professor And Head Of The Dept. Of Pediatrics, Govt. T.D. Medical College, Alappuzha and I express my sincere gratitude to all the patients included in this study

\section{Bibliography}

[1]. World Health Organization. State of hearing and ear care in the South East Asia Region. WHO Regional office for Sout East Asia. WHO - SEARO. Available at http://www.searo.who.int/link Files/Publications - HEARING - \& - EAR - CARE.pdf.

[2]. Ansari MS. Screening programme for hearing impairment in newborns: A challenge during rehabilitation for all. Asia Pacific disability Rehabilitation Journal. 2004; 15: 83-89.

[3]. Feinmesser M, Tell L, Levi H. Followup of 40,000 infants screened for hearing defect.Audiology 1982; 21 : $197-203$.

[4]. Joint Committee on Infant Hearing. American Academy of Pediatrics. American Speech - Language - Hearing Association. Directors of speech and hearing programs in State Health and Welfare Agencies. Year 2007 Position statement : Principles and Guidelines for early hearing detection and intervention programs. Pediatrics. 2007 ; 120(4) 898 - 921.

[5]. Wood S, Marcormick B, Marson S.Auditory brainstem response in Pediatric audiology. Arch Dis Child 1988; 63 : 565-567.

[6]. Erenberg A, Lemons J, Sia C, Trunkel D, Ziring P. Newborn and infant hearing loss: detection and intervention.American Academy of Pediatrics. Task Force on Newborn and Infant Hearing, 1998- 1999. Pediatrics. Feb 1999;103(2):527-30.

[7]. Vohr BR, Carty LM, Moore PE, Letourneau K. The Rhode Island Hearing Assessment Program: experience with statewide hearing screening (1993-1996). J Pediatr. Sep 1998;133(3):353-7.

[8]. Downs MP. Universal newborn hearing screening--the Colorado story. Int J Pediatr Otorhinolaryngol. Jul 1995;32(3):257-9.

[9]. Finitzo T, Albright K, O'Neal J. The newborn with hearing loss: detection in the nursery. Pediatrics. Dec 1998;102(6):1452-60

[10]. Connolly JL, Carron JD, Roark SD. Universal newborn hearing screening: are we achieving the Joint Committee on Infant Hearing (JCIH) objectives?. Laryngoscope. Feb 2005;115(2):232-6.

[11]. Synnes AR, Anson S, Baum J, Usher L. Incidence and pattern of hearing impairment in children with $=800 \mathrm{~g}$ birthweight in British Columbia, Canada. Acta Paediatr. Feb 2012;101(2):e48-54

[12]. Bess FH, Paradise JL. Universal screening for infant hearing impairment: not simple, not risk-free, not necessarily beneficial, and not presently justified. Pediatrics. Feb 1994;93(2):330-4.

[13]. White SJ, White RE. The effects of hearing status of the family and age of intervention on receptive and expressive oral language skills in hearing-impaired infants. ASHA Monogr. Oct 1987;(26):9-24.

[14]. Apuzzo ML, Yoshinaga-Itano C. Early identification of infants with significant hearing loss and the Minnesota Child Development Inventory. Semin Hearing. 1995;16:124-37.

[15]. Robinshaw HM. Early intervention for hearing impairment: differences in the timing of communicative and linguistic development. Br J Audiol. Dec 1995;29(6):315-34. Ballenger JJ, Snow. JB. Diagnostic Audiology and Hearing aids. In : Otorhinolaryngology Head and Neck surgery. 15th ed. William and Wilkins ; 1996. p. $953-73$.

[16]. Yoshinaga-Itano C, Apuzzo ML. Identification of hearing loss after age 18 months is not early enough. Am Ann Deaf. Dec 1998;143(5):380-7.

[17]. Yoshinaga-Itano C, Sedey AL, Coulter DK, Mehl AL. Language of early- and later-identified children with hearing loss. Pediatrics. Nov 1998;102(5):1161-71.

[18]. Ghogomu N, Umansky A, Lieu JE. Epidemiology of unilateral sensorineural hearing loss with universal newborn hearing screening. Laryngoscope. Jan 2014;124(1):295-300.

[19]. Fitzpatrick EM, Whittingham J, Durieux-Smith A. Mild bilateral and unilateral hearing loss in childhood: a 20-year view of hearing characteristics, and audiologic practices before and after newborn hearing screening. Ear Hear. Jan-Feb 2014;35(1):10-8.

[20]. Jane E Sewart, Aimee Knorr. Hearing Loss in Neonatal Intensive Care Unit Graduates. In:Manual of Newborn care . $7^{\text {th }}$ ed. Cloherty 2012;p.847-848.

[21]. Norton SJ, Gorga MP, Widen JE, et al. Identification of neonatal hearing impairment: summary and recommendations. Ear Hear. 2000;21:529-535.

[22]. Vohr BR, Widen JE, Cone-Wesson B, et al. Identification of neonatal hearing impairment: characteristics of infants in the neonatal intensive care unit and wellbaby nursery. Ear Hear. 2000;21:373-382.

[23]. Mishra UK, Kalitha J. Brainstem auditory evoked potential In : Clinical Neurophysiology. 2nd ed. New Delhi : Elsevier ; 2006. p.329-45.

[24]. Mollar AR, Far field auditory evoked potentials. In : Hearing 2nd ed. California : Academic Press ; 2006. p.163 - 180.

[25]. Katz J, Medwtsky L, Burkard RF. Overview of auditory Evoked potentials edited by Burkard RF and Secor C. In : Handbook of clinical audiology. 5th ed. Philadelphia : Lippincott Williams and Wilkins ; 2002, p.233 - 48.

[26]. Arnold SA : The Auditory Brainstem Response. In Roeser RJ, Valente M, Hosford H (editors) : Auditory Diagnosis, $2^{\text {nd }}$ edition. NewYork, Thieme,2007;426-441.

[27]. Jackler RK, Brackman DE. Central auditory system development and disorder. In : Neurology. 2nd ed. Philadelphia : Pennsylvania ; 2005. p.563-85.

[28]. Bess FH, Humes LE. Structure and function of the auditory system. In : Audiology : the fundamentals. 4th ed. Philadelphia : Lippincott Williams and Wilkins ; 2009, p.101 - 57.

[29]. Bluestone CD, Stool SE, Alper CM, Arjmand EM, Casselbrant ML, Dohar JE et al. ear and Related structures In : Pediatric otolaryngology. 4th ed. Saunders : Elsevier ; 2003, p.779 - 807.

[30]. Graham JM, Scadding GK, Bull PD. Audiometric Testing of children. In : Pediatric ENT. 1st ed. New York : Springer ; 2007. p.337 -50 .

[31]. Misono S, Sie KCY, Weiss NS, Huang M, Boeckh M, Norton SJ et al. Congenital cytomegalovirus infection in pediatric hearing loss. Arch Otolaryngol Head Neck Surg. 2011; 137:47-53.

[32]. Remington and Klein, Wilson, Nizet, Maldonado. Syphilis In : Infectious Disease of the fetus and newborn infant. 7th ed. Saunders : Elsevier ; 2011. p.524-63.

[33]. Maisoun AM, Zakzouk S. hearing screening of neonates at risk. Saudi Med. J. 2003 ; 24(1) : 55 - 57.

[34]. Volpe JJ, Viral Protozoan and related intraeranial infections. In : Neurology of the newborn. 5th ed. Saunders : Elsevier ; 2008. p.851-915. 77 .

[35]. Lasky RE, Wiorek L, Becker TR. Hearing loss in survivors of neonatal extracorporeal membrane oxygenation (ECMO) therapy and high-frequency oscillatory (HFO) therapy. J Am Acad Audiol. 1998;9:47-58.

[36]. Fligor BJ, Neault MW, Mullen CH, et al. Factors associated with sensorineural hearing loss among survivors of extracorporeal membrane oxygenation therapy. Pediatrics. 2005;115:1519-1528. 
[37]. Forge A, Schacht J. Aminoglycoside antibiotics. Audiol Neurootol. 2000;5:3-22.

[38]. Rotstein C, Mandell L. Clinical aminoglycoside ototoxicity. In: Roland PS, Rutka JA, editors. Ototoxicity. Hamilton, Ont: BC Decker; 2004. pp. 82-92

[39]. Fausti SA, Henry JA, Helt WJ, et al. An individualized, sensitive frequency range for early detection of ototoxicity. Ear Hear. 1999;20:497-505.

[40]. Kawamoto K, Sha SH, Minoda R, et al. Antioxidant gene therapy can protect hearing and hair cells from ototoxicity. Mol Ther. 2004:9:173-181. 